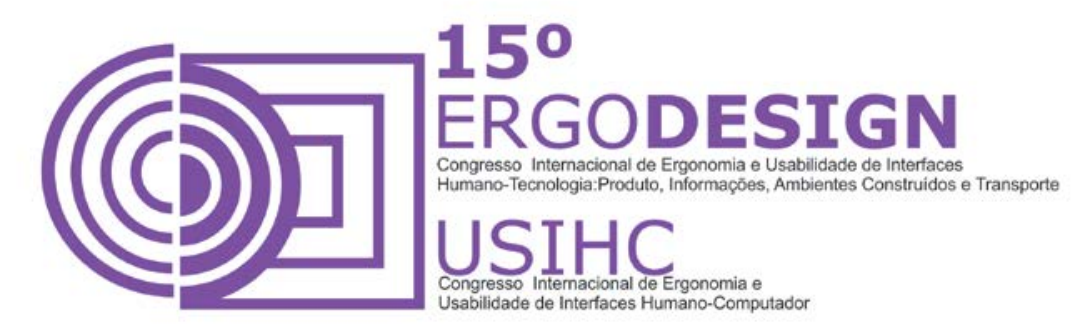

\title{
ANÁLISE DAS CONDIÇÕES DE ORIENTAÇÃO ESPACIAL DE TERMINAL DE EMBARQUE AEROPORTUÁRIO SOB O PONTO DE VISTA DOS USUÁRIOS
}

\section{REVIEW OF WAYFINDING CONDITIONS OF AIRPORT BOARDING TERMINAL FROM USERS' VIEWPOINT}

\author{
ANDRADE, Isabela Fernandes (1); \\ ANDRÉIA, Milene Sottoriva (2); \\ ZANCHIN, Mayara (3); \\ RODEGHIERO NETO, Italo (4) \\ (1) Universidade Federal de Pelotas, Mestre, Professora Assistente \\ e-mail: acessiara@gmail.com \\ (2) Universidade Federal de Pelotas, Estudante \\ e-mail: milenesottoriva@gmail.com \\ (3) Universidade Federal de Pelotas, Estudante \\ e-mail: maayfrizzo@gmail.com \\ (4) Universidade Federal de Pelotas, Estudante \\ e-mail: rodeghiero.hoe@gmail.com
}

\begin{abstract}
RESUMO
Esse artigo tem como objetivo conhecer as dificuldades enfrentadas por diferentes usuários para orientarem-se espacialmente em um terminal aeroportuário. Para isso, adotou-se o método denominado Passeio Acompanhado e utilizou-se o caso do terminal de embarque do Aeroporto Internacional de Pelotas. O estudo mostra que o terminal apresenta deficiências relacionadas à orientação espacial, principalmente, para os deficientes visuais já que o participante não conseguiu se orientar no local sendo totalmente dependente para realizar as atividades propostas e se deslocar no espaço. Como ponto positivo pode-se ressaltar as placas informativas que são legíveis (tamanho adequado, fonte e fundo contrastante), possuem tradução da informação para o inglês e a existe pictogramas associados à legenda.
\end{abstract}

Palavras-chave: Orientação espacial, Acessibilidade, Passeio acompanhado, Terminal de embarque 


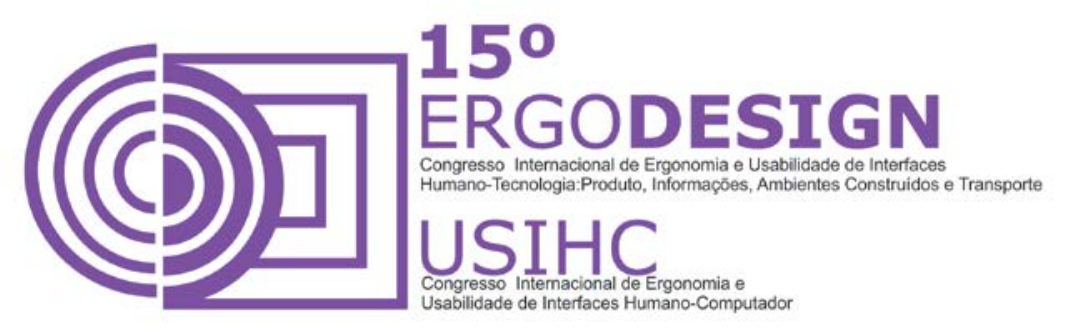

\begin{abstract}
This article aims to know difficulties confronted by different users to wayfinding in an airport terminal. For this, the method called Accompanied Walk was adopted and used the case of departure terminal of Aeroporto Internacional de Pelotas. The study discovered a great number of failures related to spatial orientation and specially visually impaired, since the interviewed showed to be totally dependent on perform the proposed activities and shift up in a space. As a positive point could be contrasted the informational signs: legible texts (source in appropriate size and contrast between figure and background), translated into English and associated with pictograms simple and intuitive recognition.
\end{abstract}

Keywords: Wayfinding, Accessibility, Accompanied walk, Airport boarding

\title{
1. INTRODUÇÃO
}

O transporte aéreo vem ganhando preferência para a realização de deslocamentos devido a sua praticidade, agilidade e, também, pela relação custo/benefício. Isso faz com que os terminais aeroportuários recebam um número significativo de pessoas com diferentes habilidades e culturas, o que exige que a edificação disponibilize ambientes espacialmente acessíveis.

De acordo com Dischinger et. al. (2012), a acessibilidade espacial pode ser associada a relação do ambiente construído com o indivíduo e, ainda, com a capacidade que este último tem de se orientar, obter informações, se deslocar e utilizar os equipamentos disponíveis no local. Tratase de um direito civil e todos os mecanismos que assegurem a sua implementação devem ser desenvolvidos. A fim de facilitar as ações de avaliação dos edifícios públicos, as autoras dividiram o conceito a partir de quatro componentes: orientação espacial, comunicação, deslocamento e uso.

Essa pesquisa tem como objetivo principal conhecer as dificuldades encontradas por diferentes usuários para se orientarem espacialmente em um terminal aeroportuário.- no terminal de embarque do Aeroporto Internacional de Pelotas. A orientação espacial é entendida como a concepção de espaços que possam ser utilizados pelos indivíduos independente de suas capacidades e/ou limitações.

Para realização dessa pesquisa em sua íntegra, adotou-se uma abordagem multimétodos pesquisa bibliográfica, visita exploratória, passeio acompanhado e grupo focal. Cabe salientar que neste artigo serão enfatizados os resultados atingidos somente a partir da aplicação do método denominado passeio acompanhado.

\section{ACESSIBILIDADE ESPACIAL}

De acordo com a Constituição Brasileira (1988), a igualdade é um direito básico de todos os brasileiros ou residentes no país. Dessa forma, a falta de acessibilidade é uma infração à lei a partir do momento em que o indivíduo se torna incapacitado ou dependente para realizar alguma atividade - sendo assim - desigual ao restante da população. 


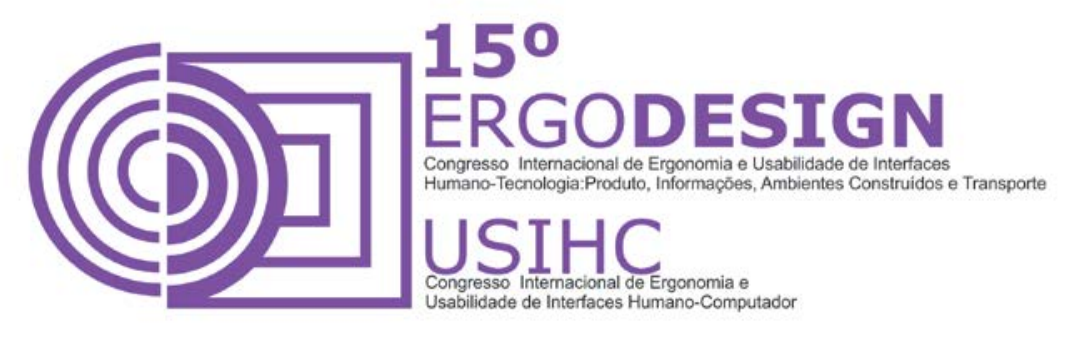

Partindo desse pressuposto, é importante analisar as condições de acessibilidade espacial nos ambientes públicos e sua implantação para que, assim, o direito de igualdade seja garantido fazendo com que toda população tenha acesso aos mesmos. De acordo com Bins Ely (2004), a acessibilidade espacial pode ser definida como a possibilidade de acesso aos mais variados lugares e atividades, como também o uso de seus equipamentos de maneira independente. Para garantir a acessibilidade espacial nos ambientes é necessário conhecer as dificuldades e necessidades de cada indivíduo e, assim, adaptar o meio para que sejam atendidos aos quatro componentes definidos por Dischiger et. al. (2012): comunicação, deslocamento, uso e orientação espacial.

A comunicação diz respeito às possibilidades de troca de informações interpessoais e entre indivíduos e equipamentos de tecnologia assistiva, como por exemplo, telefones especiais para surdos e terminais de computadores em aeroportos, como também, cardápios em Braille nos restaurantes.

O componente deslocamento refere-se à possibilidade de qualquer pessoa movimentar-se ao longo de percursos horizontais e verticais, como escadas, corredores e elevadores, de forma independente, segura e confortável.

O uso condiz com a possibilidade efetiva de participação e realização de atividades por todos os usuários do espaço.

A orientação espacial - foco desde trabalho - é a capacidade do individuo de saber onde está e para onde ele vai no espaço. Este componente pode ser definido em duas diferentes categorias de acordo com Bins Ely (2004): fenômeno estático e fenômeno dinâmico.

O fenômeno estático consiste em referenciar mentalmente um lugar para se situar em relação ao mesmo. Esta representação mental, denominada de "mapa cognitivo" ou "mapa mental", é composta de uma série de visões que as pessoas fazem do ambiente, integrando num todo aquilo que é percebido em partes. Uma pessoa é considerada bem orientada espacialmente se elaborar um mapa mental do ambiente adequadamente e souber situar-se dentro desta imagem.

Já o fenômeno dinâmico trata de como os indivíduos se deslocam nos ambientes, ou como encontram seu destino, mesmo num espaço desconhecido. O processo de orientação envolve, portanto, não apenas a construção de mapas cognitivos, mas uma série de processos mentais com o objetivo de resolver questões do tipo: "como chegar a determinado lugar?".

As condições de orientação espacial estão relacionadas à capacidade do individuo de perceber, processar as informações que o meio proporciona e agir. Esse processo depende de alguns fatores, dentre eles, das informações adicionais - como placas, sinais, letreiros - e, também, da configuração arquitetônica do local. Segundo Ribeiro (2009), esta pode facilitar a orientação quando permite uma visão direta de tudo aquilo que é importante para o processo a ser realizado, seja o alcance visual ao balcão da área de check-in ou da circulação vertical que possibilita o acesso entre os diferentes pavimentos do edifício. 


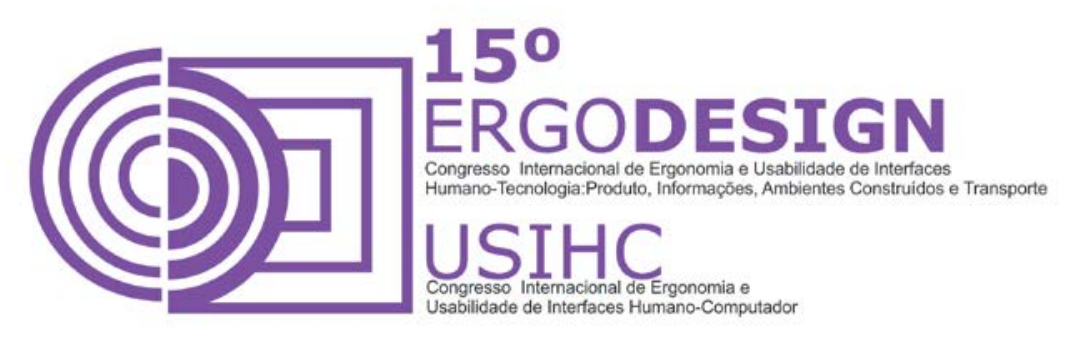

\section{METODOLOGIA}

Para o desenvolvimento deste artigo foi necessária, primeiramente, uma pesquisa bibliográfica sobre os principais conceitos envolvidos e, na sequência, foi aplicado o método denominado passeio acompanhado, definido por Dischinger (2000). Esse método permite observar a relação existente entre o espaço e o indivíduo, mostrando as dificuldades e facilidades encontradas para deslocar-se, comunicar-se, orientar-se e utilizar o espaço. Para isso, foram realizadas visitas acompanhadas ao Terminal de Embarque do Aeroporto Internacional de Pelotas com pessoas com alguma deficiência ou possível limitação no uso do espaço e, ao longo de um percurso pré-definido, verbalizavam suas dificuldades e facilidades. Além disso, os conflitos evidenciados eram registrados a partir de fotografias. Neste percurso foi solicitado que os participantes identificassem e atingissem principais atividades disponíveis no terminal como, 0 balcão do check-in, portão de embarque, sanitários e entrada/saída do edifício. Cabe salientar que a aplicação desse método agregou resultados referentes ao componente orientação espacial - foco deste estudo - mas, também, proporcionou o envolvimento com os outros componentes (comunicação, deslocamento e uso) de forma simplificada.

Foram realizados cinco passeios: pessoa em cadeira de rodas, idoso, deficiente visual, estrangeiro e surdo. Justifica-se a escolha dessa amostra diversa em função das possíveis dificuldades enfrentadas por cada um deles de acordo com Andrade (2009):

- Idoso: Pode se deparar com dificuldades em movimentar-se em função da sua idade;

- Deficiente visual: Dificuldade de orientar-se, deslocar-se e utilizar equipamentos de comunicação (placas) devido a falta ou deficiência da visão;

- Cadeirante: Possível dificuldade para se locomover e utilizar alguns equipamentos devido a restrições físico-motoras;

- Estrangeiros: Possível dificuldade em orientar-se no espaço devido à falta de conhecimento do ambiente, e também, em comunicar-se devido a diferença de idioma;

- Surdo: Pode apresentar dificuldades em comunicar-se devido à ausência de recursos para esse tipo de deficiência (interprete de libras, pessoas com domínio na Língua Brasileira de Sinais).

\section{RESULTADOS E DISCUSSÕES}

Para a realização do passeio acompanhado cada participante foi conduzido até o Aeroporto Internacional de Pelotas juntamente com os pesquisadores que, durante o percurso, apresentaram o método e como seria aplicado. O passeio foi realizado separadamente com cada colaborador.

Durante a aplicação do método os participantes eram estimulados pelos pesquisadores a verbalizar a respeito das condições de orientação do terminal aeroportuário. Além de fotografias 


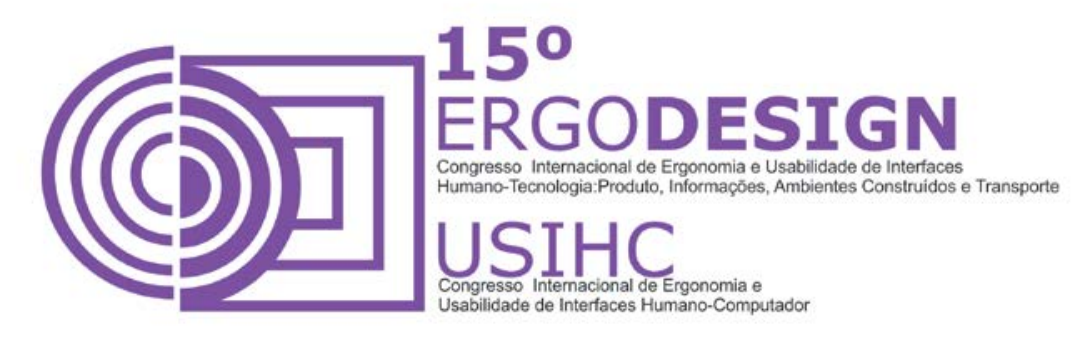

realizadas durante o passeio, foram realizadas gravações para auxiliar no tratamento dos resultados de forma mais detalhada.

\subsection{Passeio Acompanhado - Idosa}

A participante nunca havia estado em um aeroporto. Ao chegar ao terminal, a idosa rapidamente encontrou o acesso ao prédio, alegando que a entrada era visível.

Ao solicitar que localizasse o check-in (Figura 1), a participante se mostrou desorientada por não haver nenhuma sinalização no local e, assim, solicitou informação ao funcionário do aeroporto visto que nunca havia realizado check-in antes.

Logo após, a idosa identificou e se deslocou até os sanitários com facilidade e mencionou que utilizou as placas para a identificação do local.

Quando questionada a respeito do bebedouro, a entrevistada identificou o objeto visualmente, sem a necessidade de informações adicionais. Já para a localização do telefone público necessitou da sinalização visual por placas.

Para a localização da sala de embarque, a idosa utilizou o auxílio das placas de sinalização e se deslocou sem dificuldades. Ainda, elogiou o tamanho das letras disponíveis nas placas e alegou não ter dificuldades para enxergar o que estava escrito.

Ao ingressar na sala de embarque teve facilidade na localização dos banheiros pela sua sinalização a partir de pictogramas. Para localizar o portão de embarque, apesar de ter a placa indicativa, ela não está visível pois, da sala de embarque, a placa se encontra atrás da portão, ou seja, pelo lado do pátio onde se encontram as aeronaves. A participante, com dificuldade, localizou o portão visualmente (Figura 2).

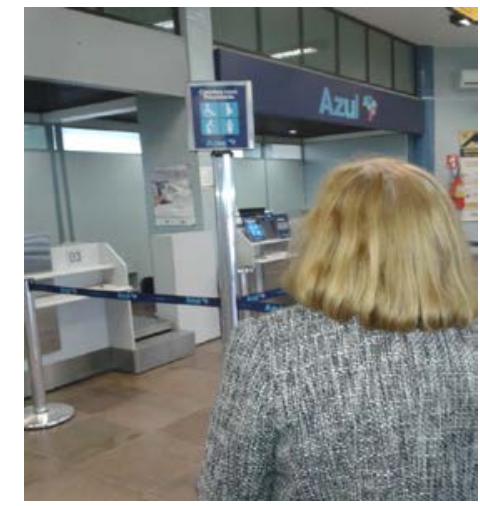

Figura 1: Idosa procurando balcão para realização do check-in.

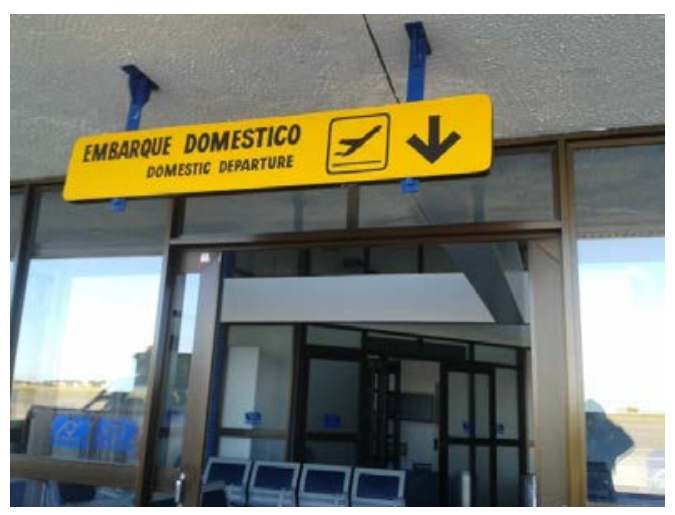

Figura 2: Sinalização para o portão de embarque. 


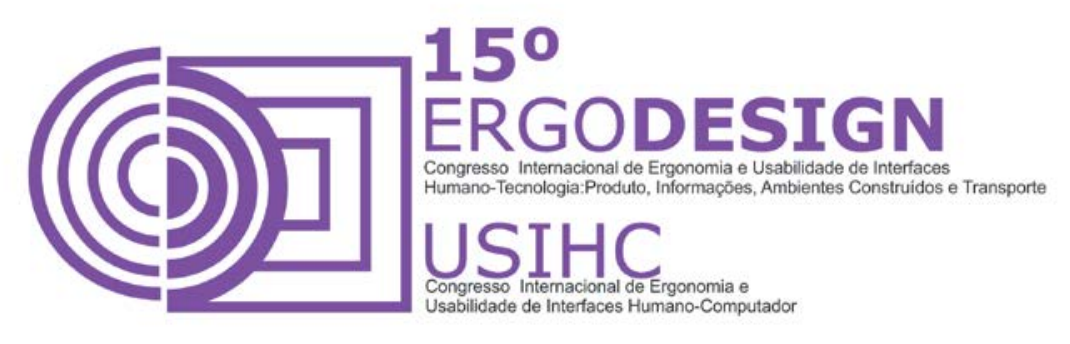

Para simular o desembarque, realizou-se o percurso entre a área de embarque e de desembarque pelo pátio. Esse trajeto foi realizado facilmente com o auxilio da sinalização por placas. Ao chegar ao desembarque, pediu-se que localizasse a esteira para a retirada das bagagens, facilmente visualizada. Nessa área também localizou os sanitários com facilidade por meio dos pictogramas.

A saída do edifício foi realizada facilmente pelo fato do terminal ser pequeno, já que a placa de indicação de saída só é possível ser visualizada no saguão de recepção.

\subsection{Passeio Acompanhado - Deficiente Visual}

O colaborador não possuía familiarização com o método a ser aplicado. Logo na chegada, o participante não conseguiu encontrar o acesso ao interior do edifício, pois não existe sinalização tátil ou sonora que conduza o deficiente visual até a porta de entrada. Conforme o entrevistado, um simples corrimão ou a instalação de piso tátil direcional seriam mecanismos eficientes. Na sua ausência, a forma adotada para localizar o acesso é através de informação oral.

Após chegar ao interior do edifício, foi solicitado que o participante localizasse o balcão de check-in. Novamente, ele não conseguiu realizar essa tarefa, pois não existe - no interior do terminal - qualquer sinalização tátil ou sonora que identifique as diferentes atividades. $O$ deficiente visual comentou que, em experiências anteriores em que precisou viajar de avião, logo que entrava no estabelecimento o segurança ou os próprios passageiros já ofereciam ajuda.

Posteriormente, foi solicitado que localizasse banheiro, bebedouro e telefone público e se dirigisse a eles, respectivamente. Totalmente desorientado, o participante utilizou informação oral para encontrar os serviços disponíveis no aeroporto. Ainda, acrescentou que poderia existir um mapa tátil logo na entrada, informando os pontos principais e sua localização.

Como pontos negativos, o colaborador apontou o pilar localizado bem na entrada dos banheiros, dificultando o livre acesso aos sanitários (Figura 3) e a falta de placas na porta dos mesmos com escrita em Braille ou alto relevo (Figura 4), não permitindo o reconhecimento de qual sexo o banheiro está destinado (se masculino ou feminino). Outro ponto levantado por ele é que, devido ao horário em que foi realizado o passeio ser de baixo movimento, torna-se mais fácil identificar a localização dos bebedouros através do barulho da água. 


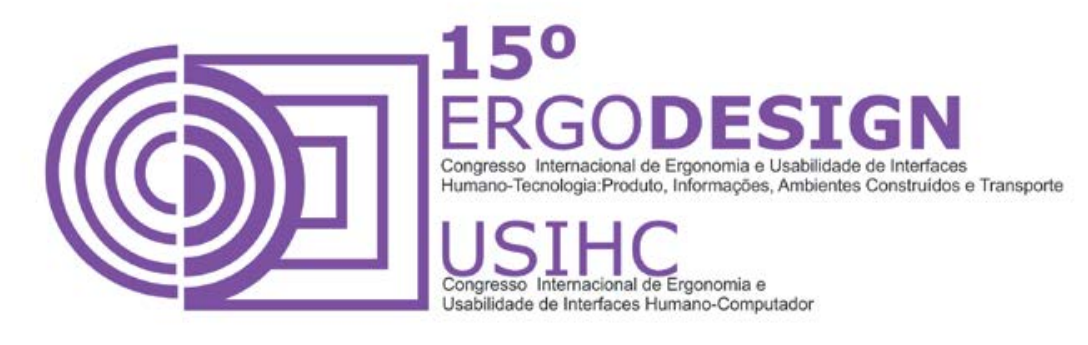

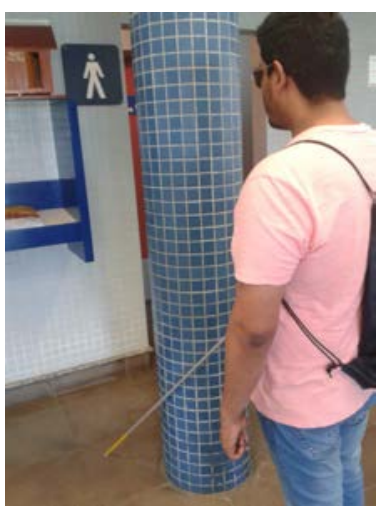

Figura 3: Pilar dificultando o deslocamento do participante.

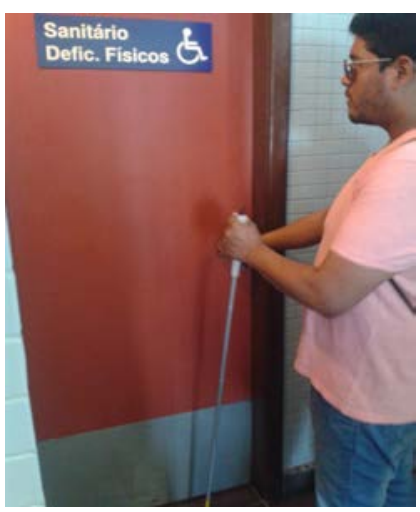

Figura 4: Falta da sinalização em Braille.

O individuo não conseguiu localizar o saguão de embarque de forma independente e comentou que, em situações como esta, necessitaria da ajuda dos funcionários. Já na sala de embarque, necessitou de auxílio para chegar até o portão. Quando saiu da sala e se dirigiu ao pátio para simular o desembarque, o participante mostrou-se desconfortável com a diferença de luminosidade (entre a artificial do terminal e a natural da rua), pois mesmo não enxergando, possui sensibilidade com mudanças bruscas de luminosidade.

Já no saguão de desembarque o entrevistado não conseguiu localizar as esteiras para a retirada das bagagens, bem como os sanitários. Manifestou que, em ocasiões como essa, seria necessário pedir informação ao segurança ou demais passageiros, pois é inexistente a sinalização tátil ou sonora no ambiente. Por fim, o colaborador não conseguiu identificar a saída do terminal e, mais uma vez, precisou de auxilio de funcionários.

\subsection{Passeio Acompanhado - Cadeirante}

Logo no desembarque do veículo, o entrevistado já elogiou a existência de rampas de acesso para cadeirantes na entrada do edifício. Ao entrar no terminal o participante levantou como ponto positivo o tamanho das portas já que não teve dificuldade para passar com a cadeira de rodas.

Posteriormente elogiou a sinalização presente em relação ao tamanho e ao contraste de cores adotado, considerando-as bem legíveis.

O participante percebeu a ausência de sinalização do balcão de check-in e alegou ter conseguido identificar o local por já ter experiência com aeroportos. Além disso, o fato do aeroporto ser pequeno e apresentar somente uma companhia facilitou o processo de identificação.

Ao se dirigir até o balcão não encontrou dificuldade no trajeto. Além disso, elogiou a forma do balcão, que possuía um vão inferior apropriado para a aproximação de cadeirantes (Figura 5). 


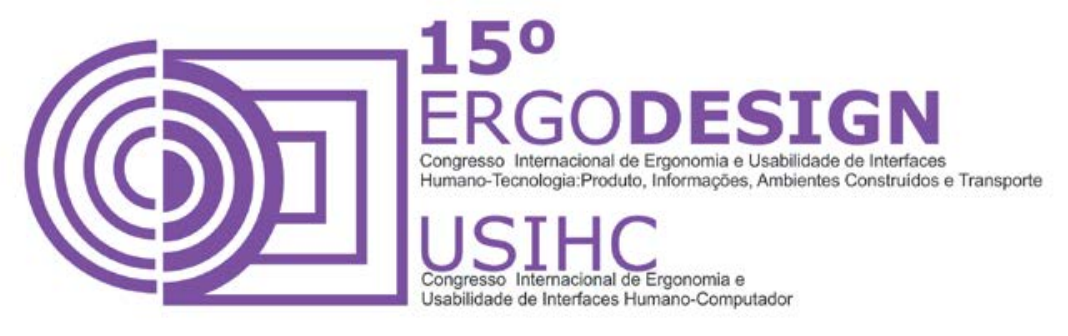

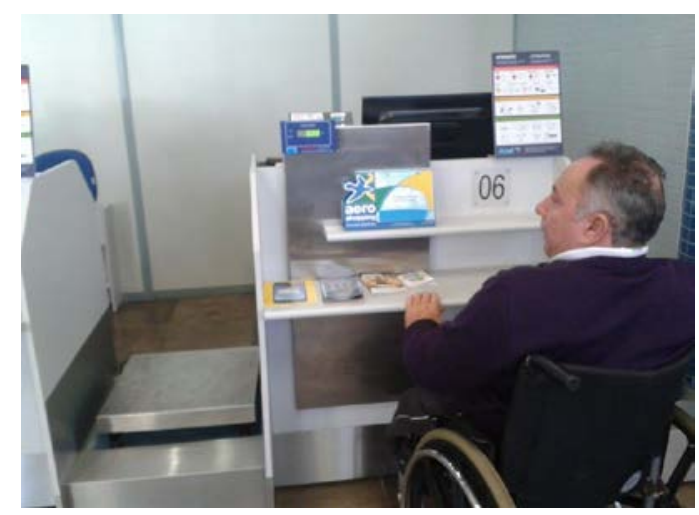

Figura 5: Participante no balcão de check-in.

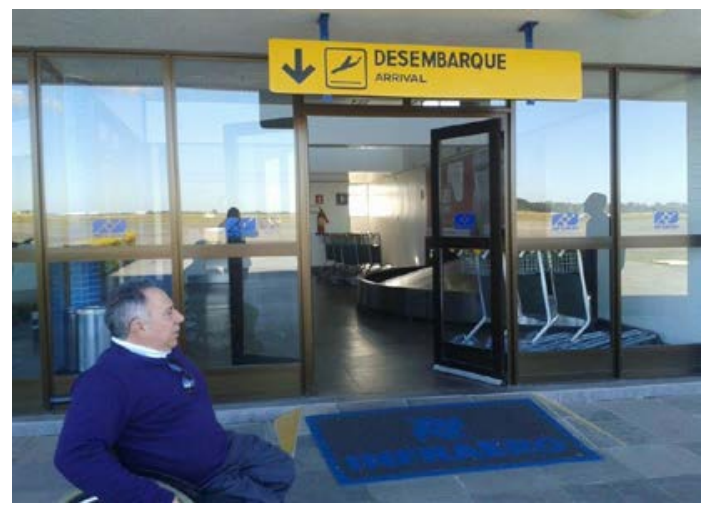

Figura 6: Simulação desembarque.

A localização do banheiro através da sinalização foi imediata; ao chegar, deparou-se com três sanitários: masculino, feminino e outro destinado aos deficientes. Fez questão de enfatizar o quão errado isto é, pois descrimina os usuários. Dentro do banheiro masculino destacou que este não tinha condição alguma de acessibilidade.

Ao entrar no banheiro acessível, indicou que o vaso sanitário, apesar de estar dentro das medidas estipuladas na NBR 9050 (dados já levantados anteriormente no método da visita exploratória), poderia ser um pouco mais alto. Em relação ao vão lateral, o qual não estava nos parâmetros estabelecidos pela legislação, mostrou ser suficientemente grande para que pudesse fazer o acesso. Logo destacou que o banheiro foi adaptado ao edifício, e não resolvido em projeto.

Após localizar o bebedouro, o cadeirante elogiou o modelo acessível e dentro da regulamentação. Da mesma forma destacou que havia um telefone público que atendia a sua demanda de altura e aproximação no terminal.

O percurso até a sala de embarque não apresentou dificuldades, porém ao entrar no local observou inúmeras inadequações, quanto à falta de banheiros acessíveis, e de um espaço adequado para que o cadeirante pudesse aguardar seu voo sem depender de um acompanhante.

Seguindo foi simulada a saída pela porta de embarque e a entrada no terminal através do portão de acesso ao desembarque (Figura 6). Este trajeto foi elogiado pelo participante por apresentar as informações corretas nas placas de sinalização e por apresentar rampas que facilitaram o acesso. Localizou a esteira para retirada de bagagens e os banheiros com facilidade, porém estes não eram acessíveis.

O participante não teve dificuldades para localizar a saída do terminal em função de seu porte e, também, das placas indicativas instaladas. 


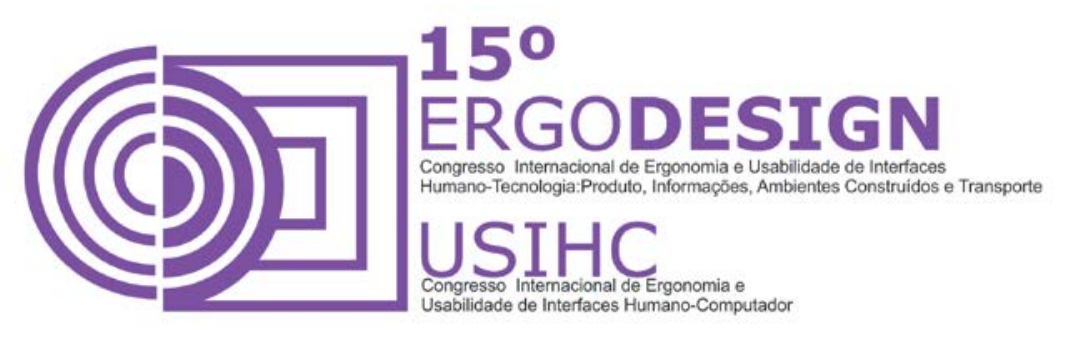

\subsection{Passeio Acompanhado - Estrangeira}

De naturalidade uruguaia, a participante ressaltou logo na chegada que a sinalização do terminal está apenas em português, o que dificulta a identificação do prédio para estrangeiros. Devido ao aeroporto ser pequeno, a identificação do local de entrada é facilitada, porém há apenas uma pequena placa confirmando o acesso principal no interior do prédio. Logo, se a porta estiver fechada, não pode ser visualizado.

O acesso ao interior do edifício ocorreu tranquilamente. Houve a percepção de falta de sinalização indicativa do balcão de check-in, informando sua localização (Figura 7).

Posteriormente, através das placas informativas dispostas no aeroporto, a estrangeira conseguiu orientar-se e localizar o banheiro, bebedouro e telefone público.

A participante levantou como ponto positivo a boa legibilidade das placas (fonte grande e tradução para a língua inglesa), além da existência de pictogramas informativos.

A sala de embarque foi identificada por meio das placas com pictograma associados aos textos, que foram ressaltadas como ponto positivo para garantir uma boa orientação. Os sanitários da sala de embarque estão apenas indicados como pictograma universal e isso facilitou sua identificação. Entretanto, não conseguiu localizar o portão de embarque (Figura 8), por não existir sinalização adequada.

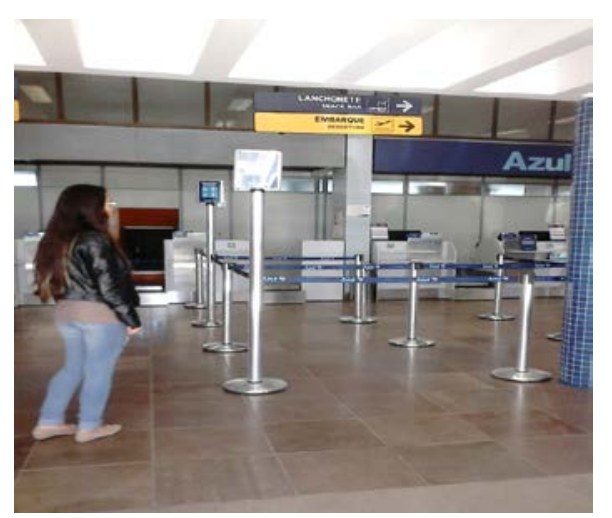

Figura 8: Localização do balcão de check-in.

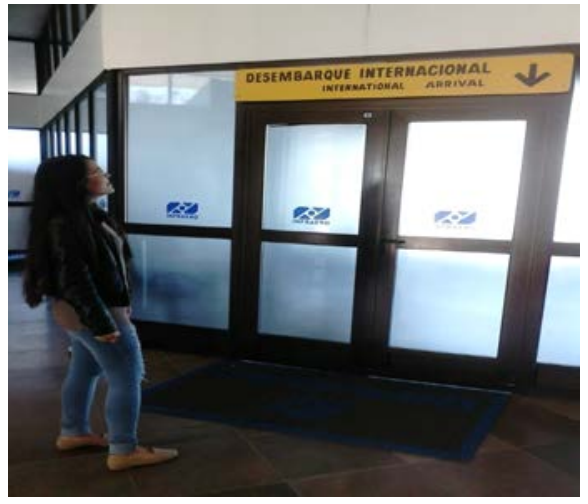

Figura 9: Identificação do desembarque.

Ao chegar ao desembarque, a localização da esteira para retirada de bagagens foi extremamente simples. Localizou os sanitários com facilidade, pela existência dos pictogramas.

Como ponto negativo, a estrangeira identificou que o texto escrito na placa indicativa de saída do edifício está apenas em português, porém, conseguiu sair do edifício pois o terminal é pequeno e isso facilitou a sua orientação. 


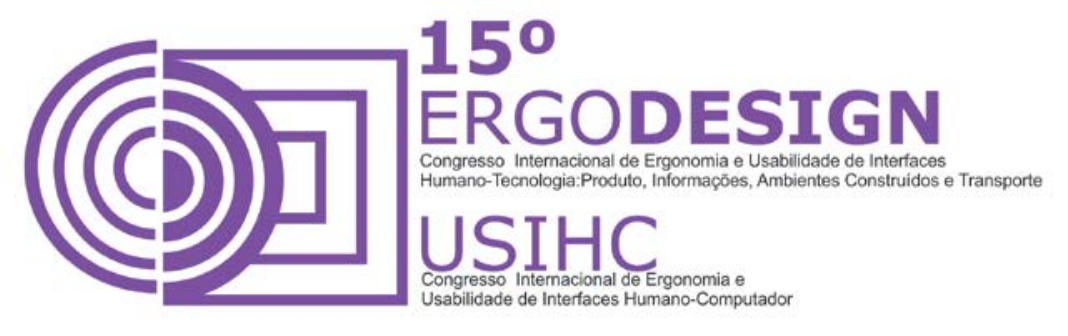

\subsection{Passeio Acompanhado - Deficiente Auditivo}

A comunicação entre os pesquisadores e o entrevistado ocorreu de forma escrita (Figura 9).

$\mathrm{O}$ acesso ao edifício foi realizado facilmente. O participante identificou de forma visual, sem a necessidade de informações adicionais. Identificou o balcão de check-in da mesma forma, já que, o objeto se encontra em frente à entrada do saguão do aeroporto, tornando-se visível.

Para a localização dos banheiros (Figura 10), o participante estava desorientado e não utilizou sistemas informativos. Com dificuldade, localizou visualmente. Logo após, para encontrar o telefone público o colaborador utilizou as placas.

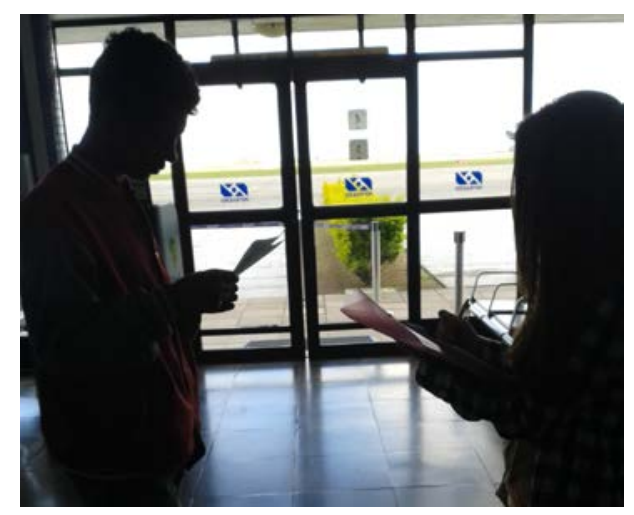

Figura 9: Comunicação de forma escrita.

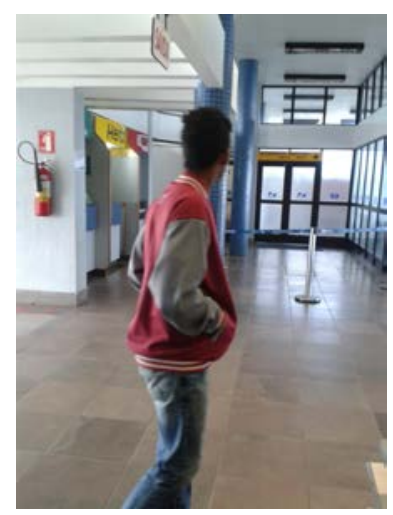

Figura 10: Participante procurando sanitários.

A sala de embarque, novamente, foi identificada através de placas. Dentro da sala os banheiros foram localizados através de pictogramas universais, sem dificuldade. O portão de embarque e os assentos de forma visual.

Ao acessar a sala de desembarque, o participante identificou a esteira para retirada de bagagens com facilidade. Também localizou os sanitários através dos pictogramas.

Mesmo com a ausência de placa indicativa de "saída" na sala de desembarque, o colaborador se deslocou até o saguão e se retirou do aeroporto com facilidade.

\section{CONSIDERAÇÕES FINAIS}

A aplicação do método, passeio acompanhado, permitiu identificar as dificuldades que os indivíduos podem encontrar no terminal de embarque do Aeroporto Internacional de Pelotas, de acordo com cada limitação/restrição. Cabe salientar a importância da participação e do envolvimento dos colaboradores no desenvolvimento do estudo em função de sua importância na proposta de melhorias em questões de acessibilidade à sociedade. 


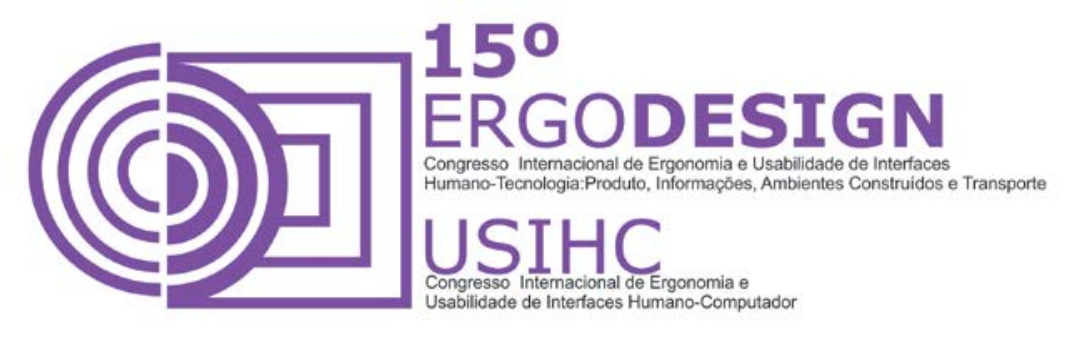

As dificuldades encontradas pelos participantes divergiram, o que permite observar as potencialidades e desconformidades do terminal de forma pontual de acordo com as estratégias adotadas por cada participante para se orientar e deslocar no espaço. A idosa, que nunca havia estado em um aeroporto, não conseguiu identificar o balcão para a realização do check-in apesar de estar localizado logo na entrada do edifício, o que pode ser justificado pela ausência de sinalização indicativa. Já o cadeirante, que já possuía experiência em aeroportos, identificou facilmente. Contudo, salientou que foi possível a identificação em função de conhecer esse tipo de ambiente.

A localização dos sanitários, bebedouro, telefone público e a sala de embarque foi desempenhada facilmente pela idosa, cadeirante e pela estrangeira a partir de sinalização visual. O deficiente auditivo, que não utilizou nenhum sistema informativo, pareceu desorientado para localizar os sanitários.

Os colaboradores mencionaram como aspecto positivo as placas informativas, alegando que estas são legíveis (tamanho adequado, fonte e fundo contrastante), possuem tradução da informação para o inglês e, ainda, existe pictogramas associados à legenda. Outro ponto a ser ressaltado é que a estrangeira e a idosa tiveram dificuldades de encontrar o portão de embarque, pois, da sala de embarque, a sinalização indicativa se encontra atrás da porta, ou seja, pelo lado do pátio onde se encontram as aeronaves. Já o cadeirante e o deficiente auditivo identificaram facilmente.

$\mathrm{Na}$ simulação do desembarque - saída pelo portão de embarque e ingresso pelo portão de desembarque - as atividades foram facilmente executadas pela idosa, cadeirante, deficiente auditivo e estrangeira através das placas de sinalização, assim como a localização da esteira para retirada de bagagens e dos sanitários da sala de desembarque.

Para a saída do edifício, os participantes exaltaram que a configuração do aeroporto - linear - e o seu porte - pequeno - facilitaram o reconhecimento da porta já que, a placa de indicação de saída só foi visualizada no saguão de recepção. Por outro lado, a estrangeira apontou como ponto negativo a placa de "saída" estar indicada apenas em português.

Questinou-se os responsáveis pela administração do Aeroporto Internacional de Pelotas à respeito da disponibilidade de um intérprete que pudesse se comunicar e sanar possíveis dúvidas de indivíduos com deficiência auditiva, mas a resposta foi negativa.

O deficiente visual apresentou dificuldades em todas as atividades propostas ao longo do percurso, e foi totalmente dependente para realizar o processo. Isso porque, o terminal estudado não apresenta sinalização acessível para esse tipo de restrição, como piso tátil, corrimão e sistema em Braille.

Assim, com o método do passeio acompanhado aplicado pode-se perceber que existem melhorias que podem ser realizadas para proporcionar condições de orientação espacial para os diferentes usuários, principalmente para os deficientes visuais, individuo para o qual 0 ambiente apresentou condições mais precárias. 


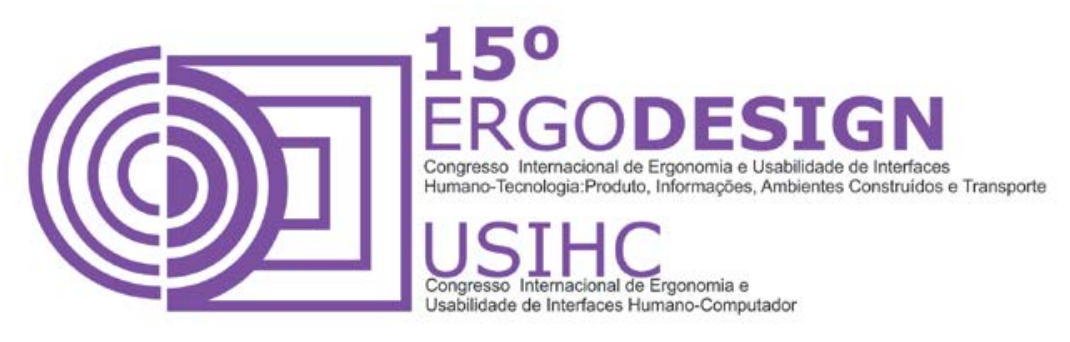

\section{REFERÊNCIAS BIBLIOGRÁFICAS}

ANDRADE, Isabela Fernandes; Edificações Históricas Preservadas: Intervir para Torná-las Acessíveis. Ação Ergonômica - Revista Brasileira de Ergonomia, Florianópolis, v7, n.2, p.80, 2009.

BINS ELY, V.M. Seminário Acessibilidade no Cotidiano. Palestrante da Mesa Redonda Estudos da Acessibilidade no Espaço Construído, com o tema Orientar-se no espaço: condição indispensável para a acessibilidade. 2004.

BRASIL. Constituição (1988). Constituição da República Federativa do Brasil. Brasília. Disponível em $<$ http://www.senado.gov.br/legislacao/const/con1988/con1988 05.10.1988/art 5 shtm> Acesso em setembro de 2014.

DISCHINGER, Marta. Designing for all senses: accessible spaces for visually impaired citizens. Goteborg, Suécia: Department of Space and Process, School of Architecture, Chalmers University of Technology, 2000.

DISCHINGER, M.; BINS ELY, V.M; PIARDI, S. Promovendo acessibilidade espacial nos edifícios públicos: Programa de Acessibilidade às Pessoas com Deficiência ou Mobilidade Reduzida nas Edificações de Uso Público. Florianópolis-2012.

RIBEIRO, LÚCIA; Onde estou? Para onde vou? Ergonomia do Ambiente Construído: Wayfinding e Aeroportos. Julho de 2009.

\section{AGRADECIMENTOS}

Agradecemos aos responsáveis do Aeroporto Internacional de Pelotas - em especial ao sr. Francisco Camejo - que cederam o espaço para a pesquisa, permitindo o acesso às áreas do edifício. 